\title{
Impact of Changing Lifestyle on Municipal Solid Waste Generation in Residential Areas: Case Study of Qatar
}

\section{Hafis Bello}

International Islamic University Malaysia, Kuala Lumpur, Malaysia

\begin{abstract}
Qatar currently has one of the highest per capita municipal waste generation in the world. The continuous increase in household wastes, and overfilled landfills threaten available spaces for urban development programmes in the country. Consequently, this study examined the lifestyle factors that have led to high municipal solid waste generation in the country. Data were gathered from both primary and secondary sources. Considering the sociocultural factors in the country, the convenience sampling technique was adopted. Thus, questionnaires were administered via online survey. At the end of the survey, 68 responses were received, and utilized for the study. The analysis of Data used the descriptive and inferential statistical tools via the SPSS 24 software. Descriptive tools used are frequency tables, bar-diagrams, line graphs, pie charts, averages, and relative importance index while Pearson Correlation was used to make inferences. The study observed a direct relationship between the increasing population in Qatar and the high municipal solid waste generation; and that $50 \%$ of the respondents have household sizes of between $4-7$ persons. Over $90 \%$ of the respondents have university education. The RII result of 3.514 out of 5 showed that kitchen waste accounts for over $70 \%$ of the household wastes in Qatar. This is followed in rank by nylon wastes while plastic wastes ranked third. Other waste components are paper and cardboard, glass, and wood and furniture. The calculated average daily waste generated per capita is $1.135 \mathrm{~kg}$. The study gathered that the municipalities, at no cost to the residents, mostly collect household wastes and most of the respondents do not sort their household wastes before disposal. With a Pearson Correlation coefficient value of 0.305 at 0.05 significant level, the study indicated a moderate positive relationship between household size and waste generated from the households. Other socio-economic lifestyle variables such as income level, education factor, and age did not prove to have such significant relationship with municipal solid waste in the area. The study recommended that in addition to coordinated sensitization programmes of waste sorting from the source, the government should set a weight limit of $7 \mathrm{~kg} / \mathrm{household} \mathrm{per} \mathrm{day.} \mathrm{Any} \mathrm{household} \mathrm{whose} \mathrm{wastes} \mathrm{exceed} \mathrm{this} \mathrm{set} \mathrm{level} \mathrm{should} \mathrm{be} \mathrm{charged} \mathrm{for} \mathrm{per} \mathrm{kilogram} \mathrm{on}$ the extra weight at the end of each month.
\end{abstract}

Keywords: Municipal solid waste; Water pollution; Climate changes; Sustainability

\section{Introduction}

\section{The concept of municipal solid waste and lifestyle changes}

This chapter discusses the key concepts in municipal solid waste management and lifestyle changes. As an introductory chapter, key research areas were defined. This include the background to the study, statement of research problem, aims and objectives of the study, research questions, justification of the study, implications of the study on urban design, scope of study as well as the Islamic thoughts on municipal solid waste management and lifestyle factors.

\section{Background to the study}

Efficient waste management is an essential component of healthy human society and sustainable environment. Naturally, all forms human activities generate different types of wastes that must be appropriately disposed and efficiently managed. There has been a global increase in the volume of waste generated especially in urban centres [1] with the attendant effects on the increasing emissions of greenhouse gases (GHG) and climate changes; water pollution, drainage blockage, flooding, breakdown of the ecosystems, outbreak of epidemic diseases and related health problems.

Solid waste refers merely to unwanted or useless non-liquid waste generated from residential, commercial and industrial activities in a given area or municipality. Municipal solid waste (MSW) is a non-air and sewage emissions created within and disposed of by a city, including household garbage, commercial refuse, construction and demolition debris, dead animals, and abandoned vehicles [2]. Municipal solid waste is a significant component of wastes generated in the urban centers, and the majority of substances composing municipal solid waste include paper, vegetable matter, plastics, metals, textiles, rubber, and glass [3].

To achieve environmental quality and improved human health, MSW should be appropriately disposed of [4] as they have both direct and indirect effects on man and his environment. These include exposure to toxic chemicals through the air, water and soil media; exposure to infection and biological contaminants; stress related to odor, noise, vermin and visual amenity; risk of fires, explosions, and subsidence; spills, accidents and transport emissions [5,6] classified the environmental impacts into six categories- global warming, photochemical oxidant creation, abiotic resource depletion, acidification, eutrophication, and eco-toxicity to water.

Lifestyles refer to specific forms of how individuals live and interpret their lives in a social context. To describe or re-construct a lifestyle from a macro-perspective three core dimensions have to be combined: social status or class; attitudes and preferences; and behavior [7]. These dimensions have substantial impact on the level of waste generated

*Corresponding author: Hafis Bello, International Islamic University Malaysia, Kuala Lumpur, Malaysia, Tel: + 60 (3) 6196 4000; E-mail: hafisbello@gmail.com

Received April 03, 2018; Accepted April 16, 2018; Published April 23, 2018

Citation: Bello H (2018) Impact of Changing Lifestyle on Municipal Solid Waste Generation in Residential Areas: Case Study of Qatar. Int J Waste Resour 8: 335. doi: 10.4172/2252-5211.1000335

Copyright: (c) 2018 Bello $\mathrm{H}$. This is an open-access article distributed under the terms of the Creative Commons Attribution License, which permits unrestricted use, distribution, and reproduction in any medium, provided the original author and source are credited. 
in a particular household. In addition, advancement in technology as well as regular activities- purchases and product packaging at shopping malls, food storage and refrigeration, awareness of expiry date, public health announcements on particular kind of goods, school resumption and closure periods, regular changes in tastes, change in weather conditions- could have significant impact on the volume of solid waste generated.

\section{Statement of the problem}

MSW is one of the most significant health and environmental problems facing the Arabian Gulf [8]. Al Maaded noted that the Gulf region that once recorded as low as $300 \mathrm{~g} /$ capita/day became one of the highest solid waste generators in the world after the discovery of oil in the early thirties. This spiraled fast development, the explosion of the construction industry, increased migration, among other factors [9]. The changing economic situation also resulted in a sharp increase in ruralurban migration with a consequent increase in urban solid waste [10]. Zafar noted that lavish lifestyle, ineffective legislation, infrastructural challenges, nonchalance attitude and lack of environmental awareness are the primary factors responsible for the growing waste management problem in the Middle East. High standards of living coupled with the lack of waste collection and disposal facilities have transformed these wastes into a liability [11]. Consequently, this study aims to examine lifestyle changes that have influenced the high per capita rate of solid waste generated in Qatar.

\section{Aims and objectives}

This study aims to examine the impact of lifestyle changes on increasing solid waste generation in Doha district.

The objectives include:

1. Identify specific components of the municipal solid wastes in Qatar;

2. Examine lifestyle factors that have contributed to the sharp increase in per capita municipal solid waste generation in Qatar;

3. Identify ways to enhance municipal solid waste management in Qatar; and

4. Propose strategies to reduce solid waste generation, and ensure sustainable lifestyle.

\section{Research questions}

- What is the major component of waste generated in Qatar?

- What have lifestyle factors led to a rise in per capita municipal solid waste generation in Qatar?

- What ways can municipal solid waste management are enhanced?

- What strategies can be implemented to minimize the rate of MSW in the study area?

\section{Justification of study}

The importance of the clean environment to a healthy living condition for human beings cannot be over-emphasized [12]. MSW is harmful to human health. This is the reason different governments devote a substantial part of their annual budget for solid waste management. According to the World Bank report [1] solid waste management takes so many resources that it is sometimes the only item carried out by some local government councils in developing countries. The four significant methods adopted in solid waste disposal and management- landfilling, incineration, composting and anaerobic digestion- require substantial spatial, human, material and financial resources.

\section{Implications for urban design}

Urban design is integrated and multi-disciplinary of shaping the form and structure of a city and establishment of frameworks and processes that facilitate sustained growth and development for regular urban life. The urban design theories thus deal with issues of space allocation for various land uses including spaces for approved dumpsites and landfilling.

Zafar observed that landfilling is the predominant method of solid waste disposal in Qatar. The collected MSW are transported to various transfer stations from where it is sent to any of the three purposedesignated landfills -Umm Al-Afai for bulky and domestic waste; Rawda Rashed for construction and demolition waste and Al-Krana for sewage wastes. The government has also established a new Domestic Waste Centre (DSWMC) to facilitate processing and recycling of MSW.

A visit to these landfills showed that they are filled. Additionally, the use of ample space of land for MSW landfilling purpose is a tremendous opportunity cost especially in a country with limited land space such as Qatar. These spaces could also be used for a developmental purpose that would generate higher GDP for the government. While the government is spending substantial annual budgetary provision on recycling and expanding landfills, there is the need to examine causes of the rising MSW generation in the country and proffer adequate solution to mitigate the rate. Furthermore, the extreme humanitarian crises, increasing of malnutrition and death from hunger in different parts of the world also necessitate increasing awareness and consciousness in consumption patterns and food wastage.

This study will thus suggest lifestyle changes that could be encouraged among residents and citizens of Qatar to free up land spaces and government resources on waste management. Such resources can then be channelled into other productive sectors of the fast developing national economy.

\section{Materials and Methods}

The mixed method approach was adopted in this study. The investigation was being undertaken using survey research leveraging on questionnaires administration to target population, and gathering of waste data from the target households.

\section{Description of population study}

Due to the nature of the study, the cultural environment and access to information; the study adopted different strategies for the qualitative and quantitative data collection. This is essential to ensure proper examination of the subject matter.

\section{Qualitative data}

The population of the study shall cover households in Qatar. Doha, the capital of Qatar, displays the economic, political and social features of a capital city. The city has the highest planning zones in the country (Zones 1-49, and Zones 60-70). The municipality also accounts for most significant \% age of the population in Doha- $46.9 \%$ in 2010 and $39.8 \%$ in 2015 , while the total human population in the Municipality is 956,457 . The total number of the occupied housing unit in Doha is 117,746 [13]. Consequently, Doha accounts for the highest volume of 
Citation: Bello H (2018) Impact of Changing Lifestyle on Municipal Solid Waste Generation in Residential Areas: Case Study of Qatar. Int J Waste Resour 8: 335. doi: 10.4172/2252-5211.1000335

Page 3 of 7

municipal solid waste generation in Qatar (Figure 1).

\section{Quantitative data}

Quantitative data gathered from secondary sources are adapted in this study. The data covered daily household wastes generated for 3 months (February, March and April 2015) [14].

\section{Sample selection/size}

The convenience sampling technique was adopted in the studythe researcher meets with individuals that are available and willing to participate in the study rather than selecting from the entire population.

$$
S S=\frac{\left\{z^{2} \times p \times(1-p)\right\}}{c^{2}}
$$

Where;

$\mathrm{Z}=$ confidence level $=90 \%$ ( which corresponds to 1.645 )

SS=Sample Size

$\mathrm{P}=$ response distribution $=50 \%$

$\mathrm{C}=$ confidence interval $=9 \%$

Therefore, after solving the equation:

$$
s=\frac{\left\{1.645^{2} \times 0.5 \times(1-0.5)\right.}{0.09^{2}}=83.52
$$

It means that at a confidence level or error margin of $9 \%$, the sample size for this study is 83.52 households. At the end of the questionnaire administration period, only 68 questionnaires/responses were gathered. This represented $82 \%$ response rate from the sample size.

\section{Description of the sampling technique employed}

This sampling technique is highly essential in a country like Qatar due to cultural factors, different work times, and high demand for privacy as well as limited resources. It also enables the respondents to complete the questionnaires (via Google Forms) easily via their mobile phones or computer systems at their most convenient time, without any interference, or bias, influenced by the researcher. Some of the respondents expressed their satisfaction with the simple approach adopted in the questionnaire noting that it took them 3 minutes or less

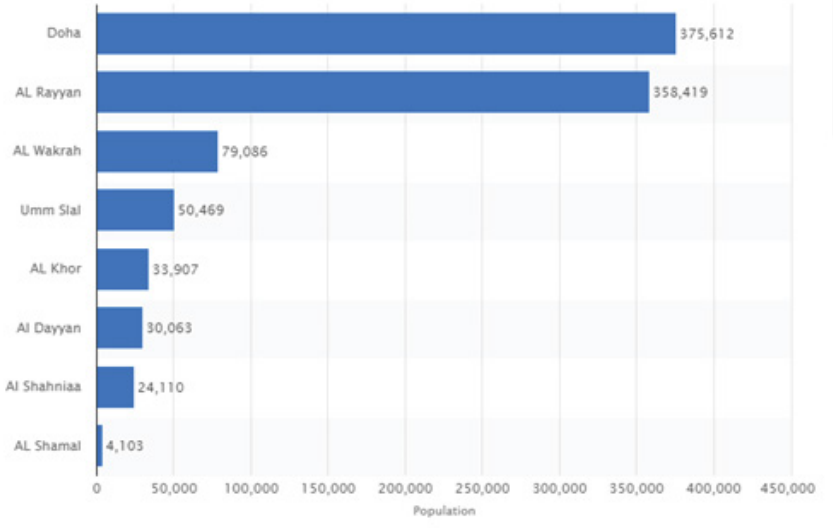

Figure 1: Number of households in Qatar in 2015. to complete it.

\section{Research instrument}

Both primary and secondary data were utilized in this study. Information utilized in the study were gathered through:

a. Design and administration of questionnaire to the target respondents;

b. Waste generation data from the houses in the study area;

c. Theoretical background information that would be gathered through review of related literature on consumption pattern and Municipal Solid Waste Generation; and

d. Journals, government publication, statistical documents, and gazettes.

\section{Analysis of Data Generated on Municipal Solid Waste and Lifestyle Factors in Qatar}

\section{Section A}

The information contained in Table 1 indicates that the respondents cut across many municipalities in Qatar. It also indicates that Doha has the highest response rate (50\%), followed by Al-Rayyan (25\%). Other respondents live in Al-Wakrah (8.8\%), Al-Khour (7.4\%), Umm Salal (7.4\%) and Al-Shahaniyya (1.5\%). The high response rate from Doha and Al-Rayyan could be attributed to the fact that the two areas are the most populated municipalities in Qatar.

Respondents in the study cut across different age groups. As indicated in Figure 2, most of the respondents are between 26-40 years of age $(59.8 \%)$. The remaining respondents are either between 18 -25years (20.9\%) or $41-60$ years $(20.9 \%)$. The findings indicate that most of the respondents are young and within the working class category.

The pie chart below indicates that there is fair gender representation in the survey with a slightly higher margin by the female category (51.5\%) The ease of completing the questionnaire via devices could have contributed to good gender representation (Figure 3).

The information contained in the pie chart indicates that the respondents belong to different occupation category. A more substantial number of respondents work in the private sector of the economy (41.2\%). This is strictly followed by respondents who work in public sector organizations $(22.1 \%)$. The remaining respondents are students $(17.6 \%)$, either self-employed $(8.8 \%)$ or unemployed $(10.3 \%)$. The occupation distribution of respondents in different categories could further help in determining if the occupations of respondents have any impact on their waste generation behaviours (Figure 4).

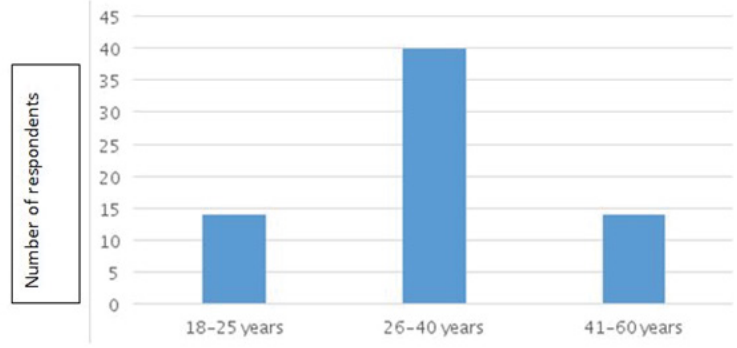

Figure 2: Age of respondents. 
Citation: Bello H (2018) Impact of Changing Lifestyle on Municipal Solid Waste Generation in Residential Areas: Case Study of Qatar. Int J Waste Resour 8: 335. doi: 10.4172/2252-5211.1000335

Page 4 of 7

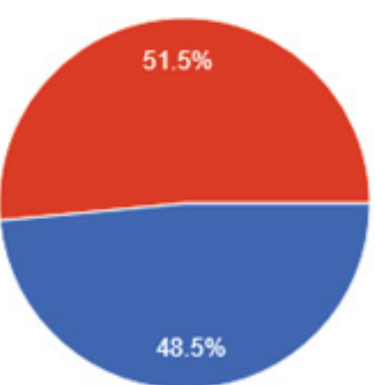

Male 5

Female لكي

Figure 3: Gender of respondents.

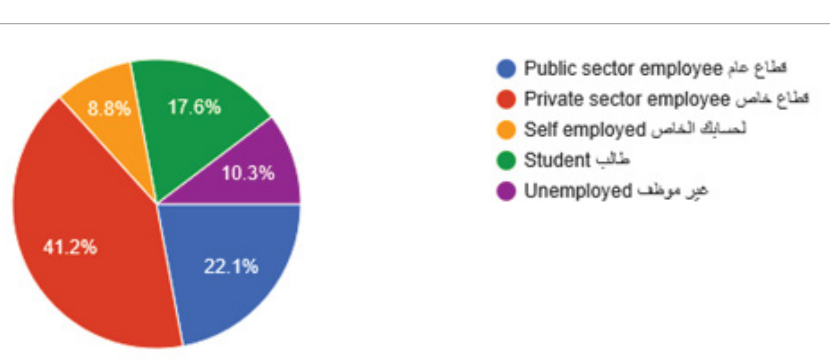

Figure 4: Occupation of respondents.

The information contained in the monthly income Table 2 shows that most of the respondents earn between QR 5000 - QR 20,000. The category accounts for $47 \%$ of the total respondents while $33.8 \%$ earn below QR 5000 . The only $4.4 \%$ of the respondents earn between QR 20,001 - QR 30,000 while the remaining respondents earn above QR $30,000(14.7 \%)$. As a regular occurrence in most economies, income levels are closely tied to education level and occupation status of the respondents. The cross tabulation on income level and education level of respondents further show relationship between the education level of the respondents and their monthly income (Table 2).

Related to the issue of income is the education level of the respondents. The bar diagram below indicates that most of the respondents have B.Sc. degree (54.4\%). This is followed closely by respondents who have MBA/M.Sc. educational degrees (27.9\%). The only $11.8 \%$ of the respondents have a high school certificate, while the remaining respondents have obtained their Ph.D. degrees. Usually, education is viewed as a factor in lifestyle patterns. Hence, the educational level will be cross-tabulated with other variables (Figure 5).

The household of respondents is essential to solid waste estimates. The information contained in the pie chart below indicates that as high as $50 \%$ of the respondents have household sizes of between 4-7 persons, while $36.8 \%$ of the respondents have household sizes of 2-3 persons. The remaining respondents have household sizes above seven persons. This aligns with the report of the Qatar Statistics Authority that the average household size in Qatar is 3.9 (Figure 6).

The line graph below indicates that most of the respondents live in flat houses $51.5 \%$. Remaining respondents live in courtyard housing $(16.2 \%)$, compounds $(16.2 \%)$, shared apartments $(11.8 \%)$ or a villa (4.4\%) (Figure 7).

The shift from the traditional form of housing to the majorly flat type of housing could be due to the economic progress being experienced in the country as well as the changing needs of the significant young and working-class population in Qatar.

\begin{tabular}{|c|c|c|}
\hline Municipality & Number of respondents & Percentage \\
\hline Al-Khour & 5 & 7.352941 \\
\hline Doha & 34 & 50 \\
\hline Al-Rayyan & 17 & 25 \\
\hline Umm Salal & 5 & 7.352941 \\
\hline Al-Wakrah & 6 & 8.823529 \\
\hline Al-Shahaniya & 1 & 1.470588 \\
\hline Total & 68 & 100 \\
\hline
\end{tabular}

Table 1: Distribution of respondents across the municipalities.

\begin{tabular}{|c|c|c|}
\hline \multicolumn{1}{|c|}{ Frequency } & Percent \\
\hline Below QR 5000 & 23 & 33.8 \\
\hline QR 5000-QR 10000 & 13 & 19.1 \\
\hline QR 10,0001-QR 20,000 & 19 & 27.9 \\
\hline QR 20,001-QR 30,000 & 3 & 4.4 \\
\hline Above QR 30,000 & 10 & 14.7 \\
\hline Total & 68 & 100 \\
\hline
\end{tabular}

Table 2: Monthly income of respondents.

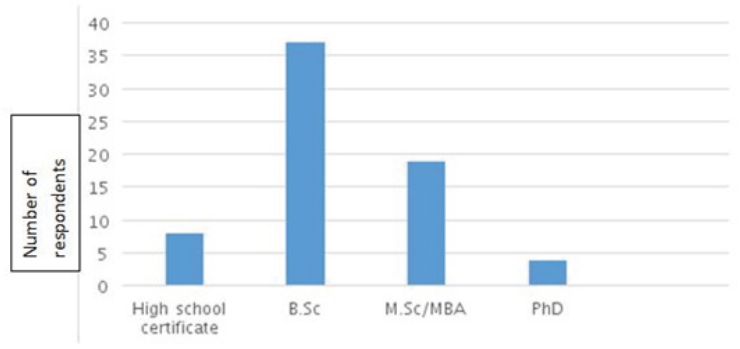

Figure 5: Education of respondents.

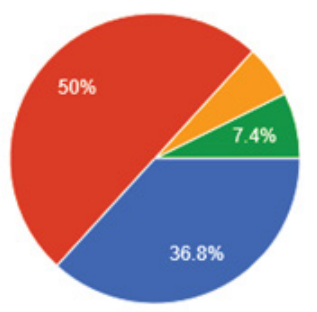

2-3 persons تشانص

4-7 persons تيناص

7-10 persons انشفلص

كثر هن 10 انغاص Above 10 persons

Figure 6: Household size of respondents.

\section{Section B}

This section examines the waste generation behaviors of the respondents. Some of the issues examined include nature of waste generated, waste separation and disposal practices as well as payment for solid waste disposal.

The information contained in the bar diagram above indicates that the respondents have different daily waste generation habits. Nonetheless, almost all the respondents noted that they generate kitchen wastes from their households. This supports the notion that the respondents mostly eat at home, which naturally means the generation of kitchen wastes. An equally high number of respondents noted that they generate paper and cardboard waste $(69.1 \%)$, plastic waste $(66.2 \%)$, and Nylon (54.1\%). Only a few respondents generate glass waste $(25 \%)$, metal waste $(8.8 \%)$, and wood and furniture waste $(4.4 \%)$ on a daily 


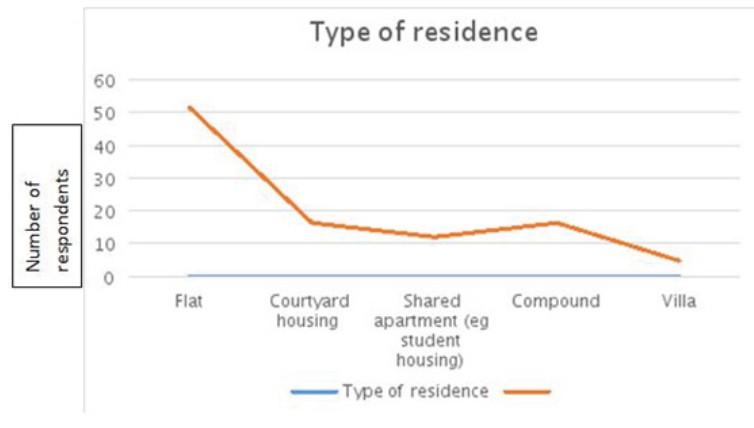

Figure 7: Type of residence.

basis (Figure 8)

\section{Results and Discussion}

Qatar is one of the wealthiest countries in the world. The country has continued to attract human and other resources to fast tracks its developments plans especially ahead of the hosting of the 2022 World Cup.

This study observed a direct relationship between the increasing population in Qatar and the high municipal solid waste generation. It was further noted that Qatar has one of the highest per capita waste generation in the world.

The current waste management system in Qatar is highly inadequate to meet with the growing population of the country. This could also be observed in the closure of the Umm-Afal landfill as it is filled beyond capacity.

This study showed that Qatar population is still mostly young as over $80 \%$ of the respondents are between $18-40$ years of age. The study also indicated that the respondents belong to different occupation category- public sector organization, the private sector, self-employed, students and the unemployed; and a more significant number of respondents work in the private sector of the economy $(41.2 \%)$. Most of the respondents earn between QR 5000 - QR 20,000; and a good proportion has B.Sc. degree (54.4\%). This is followed closely by respondents who have MBA/M.Sc. degree (27.9\%).

On the household sizes, the study indicated that as high as 50\% of the respondents have household sizes of between 4-7 persons, while $36.8 \%$ of the respondents have household sizes of 2-3 persons. Most of the respondents in the study area live in the flat type of houses, and most of them eat food prepared at home on a regular basis. The study also showed that most of the respondents visit the malls twice a week (35.3\%), while $33.8 \%$ visit once a week.

On waste generation practices, the study indicated that almost all the respondents generate kitchen wastes from their households. This supports the notion that the respondents mostly eat at home, which naturally means the generation of kitchen wastes. An equally high number of respondents generate paper and cardboard waste $(69.1 \%)$, plastic waste $(66.2 \%)$, and Nylon $(54.1 \%)$. Only a few respondents generate glass waste (25\%), metal waste (8.8\%), and wood and furniture waste $(4.4 \%)$ on a daily basis. The study gathered that household wastes are mostly collected from the residential areas on a daily basis by the municipalities, and at no cost to the residents, and most of the respondents do not sort their household wastes before disposal.

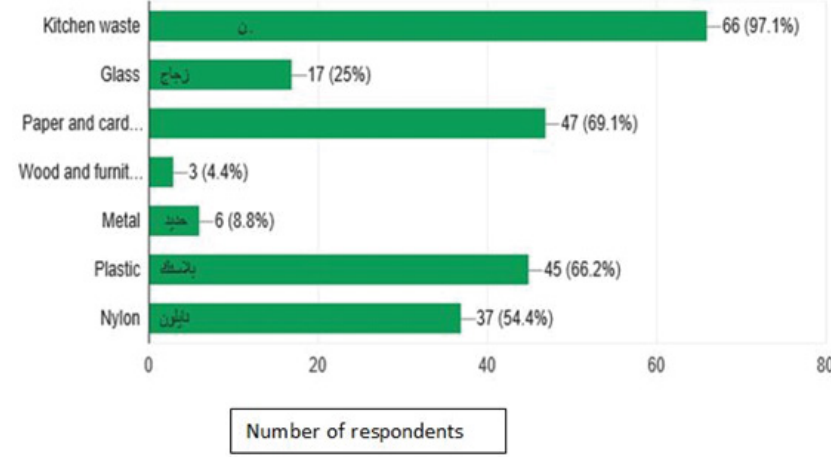

Figure 8: Nature of household waste.

The level of generation of these household waste components however vary Using the Relative Importance Index (RII), the study gathered that kitchen waste is the highest waste component generated in the households. The RII result of 3.514 out of 5 showed that kitchen waste accounts for over 70\% of the household wastes in Qatar. This is followed in rank by nylon wastes while plastic wastes ranked third. Paper and cardboard waste; glass waste, and wood and furniture waste ranked fourth, fifth and sixth categories respectively. Metal waste ranked seventh thus representing the least generated waste type in the study area. Leveraging on the secondary data, the study noted that household wastes generated in Qatar vary on different days with a high likelihood of an increase in the salary payment period. The average daily waste generated per capita is $1.135 \mathrm{~kg}$.

Using Pearson Correlation statistics, the study also indicated that there is a moderate positive relationship between monthly income and age of the respondents; at a significant level of 0.01 and a Pearson correlation coefficient value of 0.399 . In addition, with a Pearson Correlation coefficient of the value of 0.331 at 0.01 significant level, the study showed that there is a moderate positive relationship between age and educational level of the respondents. In addition, with a Pearson Correlation coefficient value of 0.305 at 0.05 significant level, the study indicated a moderate positive relationship between household size and waste generated from the households. Other socio-economic lifestyle variables such as income level, education factor, and age did not prove to have such significant relationship with waste generated from the households.

\section{Implication of findings}

This study observed a positive relationship between population and solid waste generation in the Qatar. This complies with findings in most other locations examined in this research. However, it was discovered that current waste management system in Qatar is highly inadequate to meet with the growing population of the country. This could also be observed in the closure of the Umm- Afal landfill as it is filled beyond capacity.

The fact that most of the population is young and agile could help in ensure proper regulation and compliance especially they can also participate the weighing process. The diverse employment areas of productive activities zones could facilitate delivery of new policy plan on waste generation control across the strata of the society. Also, the average education level of B.Sc degree imply that residents would better understand the need for such policies and be able to contribute in the social debates on matters of solid waste control at the household levels. 
Despite the high household sizes and regular supermarket visit times, in most parts of the study area, the modified polluter pay principle (MPPP) will still promote reduction in municipal solid waste generation.

Since kitchen waste forms a largest waste component in the area, these are the need to expand waste-to-fertilizer initiative of the government. This will not only reduce the volume of waste that will end up in the landfills but will also create more jobs and income opportunities.

\section{Suggested waste reduction model for Qatar}

The research indicated that the most significant factor that determines solid waste generation in the study area is household size, while income and eating habits played contributory roles. This implies that there is the need for effective generation control mechanism. Considering the nature of the study area and cultural implications, the government of the State of Qatar advised to adopt the Modified Polluter Pay Principle (MPPP) across the municipalities. The MPPP is a model that ensures residents are charged for the wastes they generate. The model, adapted from the Swedish waste reduction strategy, ensures that households generating above $7 \mathrm{~kg}$ of municipal solid wastes daily, are charged extra QAR20/kg for the extra kilograms. Residents that fail to pay extra fee should be charged to court. The daily average waste generation capacity has been generated through multiplication of the average daily household/capita waste (1.135), average household size and number of days in month.

When residents know they will be charged for solid waste generated, they are most likely to reduce, reuse and recycle their used or waste items. This study believes that this will yield greater results than the Ontario Model that levies the producers for waste generation. The reason being that, when producers are charged any fee, there are high tendencies such fee will be passed to the consumers, a situation that will not have much impact on the waste reduction process.

\section{Contribution of the Study}

Islam clearly cautions against wasteful lifestyles and excessive consumption. The high per capita municipal solid waste in Qatar could be an indication of excessive consumption and waste generation capacities.

While examining previous works on solid waste generation in Qatar, it was observed that none of the studies genuinely examined the relationship between lifestyle changes (socio-economic factors) and municipal solid waste generation in Qatar. In addition, the few publications on the subject of household wastes in Qatar mostly focused on either recycling, waste management challenges or waste disposal challenges. None of these publications examined the impact of lifestyle variables on municipal solid waste generation in Qatar. However, this study has provided needed information on the lifestyle-solid waste generation nexus.

Furthermore, the government continues to devote the high amount of money, land spaces and other resources to accommodate the fastgrowing solid waste generated from the households. Such pattern is unsustainable and could affect other urban development programmes being implemented in Qatar. This study thus provided robust information on various lifestyle factors that contribute to the significant increase in solid waste generation in Qatar.

\section{Strategic Outcomes}

At the policy level, a finding in this study has provided a basis for the government of Qatar to better discover main factors affecting solid waste generation. The study also advised the government to implement laws that will ensure bring about implementation of the modified polluter pay principal (MPPP). Adequate monitoring and supervisory measures should be put in place to ensure broad compliance.

At the professional level, this study provided avenue for waste management experts to further understand the link between solid waste generation and lifestyle changes. The fact that most researches have been focusing on disposal and recycling at the expense of waste minimization has been the reason for continued growing investments in solid waste sector. A country with limited land spaces like Qatar cannot continue to invest in landfill expansion at the expense of other social development projects. Waste management professional now have a basis to advise the government on best approach to handle waste management issues in Qatar.

Urban designers and architects will benefit greatly from findings in the research. Urban developments will now give credence to inclusion of weighing platforms for generated wastes in each of the municipalities. Residents can weigh their waste ahead of the collection. Furthermore, location of waste disposal bins need be well planned alongside urban development programmes and designs. This would further ensure proper collection from the various households. The current where waste receptacles are just provided in front of each house is not only unaesthetic but also dangerous to health of residents as several cases of over-filled receptacles generate unwanted flies and insects.

On the academic side, the study has added to the bod $y$ of knowledge. It is arguably the first such research to examine the link lifestyle factors with solid waste generation in Qatar. The study has thus provided a basis for new discussion pattern on solid waste generation and reduction strategies in Qatar.

\section{Recommendations}

To minimize the quantity of solid waste generated from the households, the following steps are recommended:

1. The government should set a weight limit for each household in the different municipalities. This study has suggested $7 \mathrm{~kg} /$ household per day. Any house whose wastes exceed this set level should be charged for extra weight for the month. This could be QAR 20/kg for the extra kg generated.

2. Households should be encouraged to sort their waste components before disposal. Rebates or monetary rewards can be given to households that comply especially at the early adoption stages. Households that are regular in compliance can also be announced on public campaign programmes at the various municipalities.

3. In line with the Islamic principles of education and moderate consumption, the government should engage in mass education and enlightenment programmes on waste 4 Rs of waste- reduce, reuse, and recycle and recovery- across different channels - such as the majlis, schools, traditional and social media channels, mosques and religious centres and public spaces.

4. As much as possible, emphasis should be based on community participation and community-based monitoring system to ensure broad adoption and supports.

5. The government should provide different waste receptacles for each waste type to ensure each of disposal. Considering the cost, 
Citation: Bello H (2018) Impact of Changing Lifestyle on Municipal Solid Waste Generation in Residential Areas: Case Study of Qatar. Int J Waste Resour 8: 335. doi: 10.4172/2252-5211.1000335

3 to 4 houses may be linked to each set of the waste receptacles.

6. The government should develop collaborative guidelines to facilitate recycling programme and re-use of household waste components in the country.

7. Conscious efforts should be made towards ensuring adequate involvement of the private sector and other country-based charity organizations in the recycling project. Products from the recycling centers can be exported to other countries where they could value more.

8. The government should work with the shopping malls to facilitate reuse of packaging materials at the malls. Purchase discounts should be given to clients that reuse packaging materials. In addition, the use of eco-friendly packaging materials should be emphasized.

9. Companies involved in the solid waste collection at the municipalities should be encouraged to have different compartments for the waste types. The staff of such organization should be adequately trained on the use of weighing facilities to be provided. Adequate efforts should be made to ensure sorted waste items are not aggregated at the collection points as its current practices in some parts of the country today.

10. Encourage private sector to develop techniques towards using food/kitchen in fertilizer production.

11. Companies should be encouraged to produce and use only ecofriendly and reusable materials in their production processes, and product packaging.

12. Companies should adopt the buy-back mechanisms to encourage their customers to return packaging materials for a fee or lower cost on next purchase.

\section{References}

1. World Bank (2012) What a Waste World Bank Group

2. Ali M, Cotton A, Westlake K (1999) Down to Earth; Solid Waste Disposal for Low-Income Countries. WEDC Loughorough University.

3. USEPA (2013) Environmental Report. United States Environmental Protection Agency.

4. Daskalopoulos E (1998) An Integrated Approach to Municipal Solid Waste Management. Resource Conservation Recyc 24: 33-50.

5. Dolk H (2012) Methodological Issues Related to Epidemiological Assessment of Health Risks of Waste Management. Environmental and Health Impact of Solid Waste Management Activities

6. Seo S, Aramaki T, Hwang Y, Hanaki K (2004) Environmental Impact of Solid Waste Treatment Methods in Korea. J Environ Engineer 130: 81-89.

7. Reusswig F, Hermann L, Katrin G (2002) Changing Global Lifestyle and Consumption Patterns: The Case of Energy and Food. Potsdam Institute for Climate Impact Research.

8. Maaded MA, Madi NK, Kahraman R, Hodzic A, Ozerkan NG (2012) An Overview of Solid Waste Management and Plastic Recycling in Qatar. J Poly Environ 20: 186-194.

9. Centre for Environmental Studies (2001) Down to earth. New Delhi, India.

10. Indian Institute of Technology (1997) Proceeding of the workshop on solid waste management and utilization. Department of Chemical Engineering, India

11. Zafar (2016) Solid Waste Management in Qatar.

12. Bello H (2016) Assessment of Behavioural Responses to Environmental Sanitation Facilities in the Core Areas of Developing Countries: Case Study of Ikorodu, Nigeria. Int J Ecology Ecosolution 3: 12-20.

13. Ministry of Development Planning and Statistics (2017) Population Report MDPS, Qatar.

14. Farah A (2016) Sustainable Solutions for Domestic Solid Waste Management in Qatar. Qatar University, Doha. 